\title{
EXPERIMENTAL STUDIES ON RAPID BREATHING
}

\section{TACHYPNEA, Independent of ANOXemia, Resulting fRom Multiple Emboli in the Pulmonary Arterioles AND CAPILLARIES}

By C. A. L. BINGER, G. R. BROW, AND ARNOLD BRANCH

(From the Hospital of the Rockefeller Institute for Medical Research, New York, N. Y.)

(Received for publication August 19, 1924)

\section{INTRODUCTION}

Rapid breathing is often a striking phenomenon in diseases of the cardio-respiratory systems, particularly in passive congestion of the lungs associated with heart failure and, more so, in lobar pneumonia. Indeed, in pneumonia accelerated respirations may be the outstanding clinical feature of the disease and are often a sign of prognostic importance. No physician likes to see a sudden increase in the respiratory rate or a continuation of rapid respirations over a prolonged period. But the causes of tachypnea are by no means clear nor are its effects understood. Haldane and his co-workers (1) have taught that rapid and shallow breathing may lead to anoxemia which, in turn, tends to keep up the condition of rapid and shallow breathing, thus establishing a vicious cycle. Meakins (2) has presented evidence for the view that increased respiratory rate and decreased depth, as observed in pneumonia, may be in part responsible for the occurrence of the anoxemia so frequently seen in this disease. At what point the vicious cycle begins has not been fully understood, but according to these investigators, in such conditions as pneumonia, anoxemia conceivably arises from the unequal distribution of the air in the lungs. This initiates rapid and shallow breathing, thus causing severe anoxemia and, in turn, more rapid and more shallow respirations.

It has seemed to us important to inquire further into the nature of this mechanism and to investigate experimentally some of the causes and some of the effects of tachypnea. We have already ap- 
proached this problem in its relation to lobar pneumonia from several points of view. A study (3) was made of the fluctuations in lung volume throughout the course of the disease. It was found that the volume of air in the lungs varied coincidently with the clinical course of the disease, but no unequivocal correlation could be established between lung volume changes and variations in the rate and depth of respirations. A more recent study (4) of the acid-base equilibrium of the blood of patients suffering from lobar pneumonia revealed no changes which could be regarded as responsible for these abnormal respiratory phenomena.

Since neither the gross volume changes alone in the lungs, nor the chemical changes in the blood presented explanations for the functional changes in which we were interested, it seemed to us important to investigate the nervous factors concerned with the control of the respiratory rate.

From a consideration of the phenomena involved in the control of normal respiratory movements, it is apparent that certain reflex impulses, probably arising in the lungs, may be responsible for changes in the rate and depth of the respiratory excursion, and thus, under abnormal conditions, provide a means for the onset of rapid and shallow breathing. Normally, a self-regulating mechanism exists (the Hering-Breuer (5) reflex) whereby, through the function of the vagus nerves, a given respiratory phase is terminated and the reverse phase initiated. Since the description of this reflex by Hering and Breuer, it has been generally taught that the alternate distension, and collapse of the lungs provide the stimulus for limiting one respiratory phase and releasing the opposite. The true nature of the stimulus is not understood, but it is probably in some manner related to the alternate stretching and slackening of the alveolar walls during inspiration and expiration. Lumsden (6) has brought some evidence in favor of the reflex being stimulated by the alternate inrush and outrush of air over the ciliated epithelium of the trachea and bronchi. The cause of the rhythmic discharge of the respiratory center is equally as obscure. Indeed, 34 years ago Henry Head (7) made the following statement which still must be regarded as substantially true:

If we attempt to take a general survey of the nervous mechanism of respiration, we must begin by confessing that we are entirely ignorant of the cause of the 
rhythmic activity of the respiratory centre. Although the vagi play an important part in regulating the breathing they certainly are not the ultimate cause of rhythmic respiration; for rhythmic breathing still continues, although in an altered form, even after the vagi have been divided. Moreover the centre still sends out rhythmic impulses even when the medulla oblongata is separated from the rest of the brain, the spinal cord severed below the seventh cervical vertebra and the vagi, superior laryngeal, and glosso-pharyngeal nerves divided. Now whatever may be the stimulus which keeps up the activity of the respiratory centre it is certainly not of a rhythmic nature, and we are brought face to face with the difficulty that a continuous stimulus produces discontinuous activity in the organ upon which it acts. So far we are unable satisfactorily to explain why this should be, but it is one of the earliest phenomena which meet us in the study of vital activity.

In the absence of any precise knowledge as to the nature of the rhythmic impulses normally arising in the respiratory centre or of the character of the reflex impulses arising in the lungs, it is unlikely that we can arrive at any complete understanding of the disturbances of respiratory rhythm. On the other hand, a certain body of evidence exists for the belief that the afferent impulses, arising from local stimulation of the vagus nerve endings located in the lungs, may possibly account for the rapid and shallow breathing observed in such conditions as acute lobar pneumonia. Porter and Newburgh (8) observed that the dyspnea which accompanied experimental pneumonia in dogs produced by Friedländer's bacillus could be checked by vagotomy or prevented by section of the vagi previous to infection. They concluded from their experimental findings that blocking of the afferent vagal impulses saved the respiratory centre from fatigue. Other investigators have reported that local stimuli, due to irritants, (Pi.Süner (9)), or to carbon dioxide, (Scott (10)), (Pi Sũner and Bellido (11)), may bring about rapid respirations which are promptly stopped by section of the vagus nerves. This phase of the problem received renewed attention during the war when the curious disturbances of respirations present in gassed soliders and in those suffering from the socalled "effort syndrome" were observed. Haldane (12) interpreted these pathological states as due to changes in the excitability of the respiratory center rather than to alterations in the threshold of activity of the Hering-Breuer reflex. In an effort to analyze the factors involved in the tachypnea due to gassing, Dunn (13) made the 
striking observation that obstruction to the pulmonary circulation in goats, brought about by the intravenous injection of a suspension of potato starch, gives rise to a pronounced increase in the respiratory rates, unassociated with the appearance of arterial or venous anoxemia. Furthermore, he observed that vagal section prevented the onset of rapid breathing, or abolished it when it had already begun. In spite of carefully planned experiments to estimate the blood flow, arterial and venous blood pressure changes, etc., Dunn did not explain the cause of the rapid respirations which intravenous starch injections initiated, but believed them to be in some way related to spasm of the finer bronchial musculature.

It follows from the foregoing discussion that further investigation of peripheral afferent stimuli in relation to rapid breathing is necessary. This problem was the incentive for our own experiments, of which an account follows.

\section{EXPERIMENTAL}

Choice of anesthetic. Experiments on respiratory control in man, as well as in the lower animals, are complicated by voluntary, emotional, and reflex influences. To obviate these in lower animals it is usually necessary to resort to the use of an anesthetic, the choice of which is of signal importance. Depression of the respiratory centre, or inhibition of peripheral reflexes due to the anesthetic, may so alter the mechanism as to lead to false interpretations. Ordinary volatile anesthetics, such as ether and chloroform, cannot be used satisfactorily in respiratory studies. Gad (14), following the observation of Guttman (15) recommended the use of chloral hydrate. Though possibly efficient for rabbits, chloral hydrate does not wholly satisfy the requirements when dogs are being used. The effect is not sufficiently uniform or lasting. After repeated preliminary trials it was found that Luminal and Luminal Sodium (Winthrop) provided almost ideal conditions. It is used in dosages of 0.12 to 0.15 gram per kilogram given by stomach tube. Complete narcosis does not appear for 4 or 5 hours. Anesthesia is then so light and even, that a corneal reflex usually persists throughout the experiment. Breathing remains quiet and regular, usually rather slow. The arterial blood is usually about 90 per cent saturated with oxygen. The dogs retain their sensitiveness to intratracheal and intrapulmonary stimuli. For example, a fine catheter passed through the trachea into one of the smaller bronchi leading to a lobe elicits an expulsive reflex associated with changes in respiratory rate. This reflex is often completely abolished with other anesthetics, but its persistence is of importance in the study of the effects of peripheral stimuli arising in the lungs. After several preliminary experiments in which rapid breathing was induced by irritant substances (chlorine water, $\mathrm{NH}_{4} \mathrm{OH}$ ) 
we determined to repeat Dunn's experiments for the purpose of ascertaining whether obstruction to the pulmonary circulation (arterioles and capillaries) in dogs gives rise to rapid breathing.

Embolism of the pulmonary circulation produced in dogs by the intravenous injection of a suspension of potato starch

In attempting to repeat Dunn's experiments on dogs, instead of goats which he used, we were at first confronted with the appearance of sudden death before any changes in the rate of respirations occurred. We learned, however, that this could be prevented by altering the method of starch injection. It was necessary to keep the starch granules from settling by bubbling a fine stream of air through the salt solution in which they were suspended. The suspension was then allowed to run slowly and intermittently from a burette into the right external jugular vein which had been cannulated with a wide bore glass cannula.

The starch suspension used was made according to Dunn's directions by scraping a peeled potato on a grater, washing in 0.85 per cent $\mathrm{NaCl}$ solution, filtering through 6 to 8 layers of gauze, and allowing the granules to settle. The sediment was measured in a graduated cylinder and 3 times its volume of 0.85 per cent $\mathrm{NaCl}$ solution was added. Later in these experiments it was found of advantage to use a more dilute suspension : 1 part of starch to 19 parts of physiological salt solution.

Under these conditions it was observed that a certain volume of starch suspension could be injected- without producing any apparent effect. Further injection however, resulted in very definite and constant changes. The first to be observed was an increase in respiratory rate. Associated therewith was a modification of the character of the respiratory movements, the maximum excursion of the body wall shifting from the thorax to the region of the diaphragm. During the expiratory phase the abdominal muscles at the level of the diaphragm appeared to contract forcibly. The rate gradually accelerated and the depth appeared to grow shallower. At this point further starch injection almost invariably killed the dogs. Acceleration continued until the breathing became very rapid (often more than 100 to the minute) and apparently very shallow. During the period of rapid breathing the tongue and mucous membranes and the pads of the 
paws were usually bluish and dusky. After several hours of this condition respiration gradually slowed and then ceased, the heart continuing to beat for some minutes before the death of the animal.

This description may be regarded as typical of a starch experiment. It presented several facts for quantitative analysis:

(a) The relation of rapid breathing to the volume of starch suspension injected. No constant dosage could be found which would surely bring on tachypnea. Some dogs responded to one injection of $5 \mathrm{cc}$. of the $1: 4$ suspension, others required from 15 to $20 \mathrm{cc}$. With the more dilute suspension, 1:20, larger volumes were necessary, $40 \mathrm{cc}$. in one experiment.

The fact that a certain volume of starch suspension could be injected without effect on respiratory rate was shown in an experiment in which the rate remained at 16 per minute even after a total of 11 cc. of a 1:4 suspension had been injected. Not until a total injection of $15 \mathrm{cc}$. had been given did acceleration begin. The characteristic acceleration following starch embolism is seen in another experiment where, after a total of $10 \mathrm{cc}$. of 1:20 starch suspension the rate remained at 12 , but after a total of $40 \mathrm{cc}$. the rate gradually accelerated from 12 to 100 breaths per minute in the hour following injection. The data of these experiments are presented in table 1.

These facts must be regarded as significant. They suggested to us that the starch effect was probably not an irritative one, involving principally afferent impulses which might be expected to operate at once in small doses, but that the effect was related in some way to the quantitative obstruction of the pulmonary circulation.

(b) Changes in pulmonary ventilation following starch embolism. It has already been mentioned that the rapid respirations following starch injection had the appearance of being shallow. This point was definitely established by connecting a pair of flutter valves to the tracheotomy tube and collecting the animal's expired air in a Tissot spirometer in which the volume of air could be measured. In one such experiment the tidal air was $147 \mathrm{cc}$. with a rate of 14 and a minute volume of 2.06 liters before starch injection, as contrasted with a tidal air of $88 \mathrm{cc}$., a rate of 50 and a minute volume of 4.40 liters after starch injection. This is characteristic of the rapid and shallow breathing seen in disease in man in which the combined effect of 
increased rate and decreased depth leads to a greater minute volume of pulmonary ventilation, but because of the relatively larger dead air space to a decrease in effective alveolar ventilation.

TABLE 1

The effect of starch injection on respiratory rate

\begin{tabular}{|c|c|c|c|}
\hline Experiment number & Time & Total starch & $\begin{array}{c}\text { Respiratory rate per } \\
\text { minute }\end{array}$ \\
\hline 17 & $\begin{array}{l}4.29 \\
4.42 \\
4.53 \\
4.58 \\
5.15 \\
5.30\end{array}$ & $\begin{array}{l}c i . \\
0 \\
8.4 \\
11.0 \\
15.0 \\
17.0\end{array}$ & $\begin{array}{l}16 \\
16 \\
16 \\
24 \\
28 \\
38\end{array}$ \\
\hline 21 & $\begin{array}{c}11.25 \\
12.09 \\
12.10 \text { to } 12.25 \\
12.26 \\
12.29 \\
12.33 \\
12.36 \\
12.45 \\
12.55 \\
1.10 \\
1.16\end{array}$ & $\begin{array}{c}0 \\
10.0 \\
40.0\end{array}$ & $\begin{array}{r}12 \\
12 \\
\\
24 \\
30 \\
36 \\
40 \\
46 \\
54 \\
66 \\
100\end{array}$ \\
\hline
\end{tabular}

TABLE 2

Intravenous injection of potato starch

\begin{tabular}{|c|c|c|c|c|c|c|c|}
\hline \multirow{2}{*}{$\begin{array}{l}\text { Experiment } \\
\text { number }\end{array}$} & \multirow{2}{*}{ Time } & \multirow{2}{*}{$\begin{array}{l}\text { Total starch } \\
\text { suspension }\end{array}$} & \multirow{2}{*}{$\begin{array}{c}\text { Respiratory } \\
\text { rate } \\
\text { per minute }\end{array}$} & \multicolumn{4}{|c|}{ Arterial blood } \\
\hline & & & & $\begin{array}{c}\mathrm{O}_{2} \\
\text { content }\end{array}$ & $\begin{array}{c}\mathrm{O}_{\mathbf{2}} \\
\text { capacity }\end{array}$ & $\begin{array}{c}\text { Per cent } \\
\text { saturation }\end{array}$ & $\underset{\text { content }}{\mathrm{CO}_{2}}$ \\
\hline \multirow[t]{2}{*}{${ }^{\circ}$} & & $c c$. & & ool. per cont & ool. per cent & & sol. per cont \\
\hline & $4: 29$ & 0 & 16 & 14.47 & 16.63 & 87.6 & 38.85 \\
\hline \multirow[t]{2}{*}{17} & $6: 29$ & 22 & 54 & 16.76 & 20.24 & 82.8 & 35.85 \\
\hline & $6: 47$ & & 86 & 15.33 & $21.17^{*}$ & 72.4 & 30.67 \\
\hline \multirow{3}{*}{19} & $2: 40$ & 0 & 18 & 16.71 & 17.75 & 94.2 & $47.30=$ \\
\hline & $3: 33$ & 5 & 53 & 13.10 & 17.57 & 74.5 & 52.00 \\
\hline & $3: 47$ & & 73 & 10.99 & 16.48 & 66.7 & 51.60 \\
\hline
\end{tabular}

* The increased $\mathrm{O}_{2}$ capacity observed here is probably associated with concentration of the blood resulting in part from pulmonary edema. 
(c) Arterial anoxemia following starch embolism. The cyanosis of the tongue and mucous membranes which we observed after the onset of rapid and shallow breathing was not mentioned by Dunn in his experiments. Nor did he find a condition of anoxemia of the arterial blood. The occurrence of cyanosis in our experiments indicated the probable existence of arterial anoxemia. This we found to be true. In four starch injection experiments the average arterial $\mathrm{O}_{2}$ content before injection was 14.73 volumes per cent as compared with 11.74 volumes per cent after embolism, the average $\mathrm{O}_{2}$ capacity being 16.49 volumes per cent before and 16.31 volumes per cent after embolism. These changes resulted in an average percentage saturation of 89.3 before embolism and 71.6 after. The detailed findings in two of these experiments are shown in table 2.

(d) Effect of oxygen inhalation on anoxemia and tachypnea resulting from starch embolism. To determine the relation between rapid and shallow breathing and anoxemia the following experiment was performed:

Experiment 21. A dog weighing $10.5 \mathrm{~kg}$. was given 1.65 grams Luminal by stomach tube. Three and one-quarter hours later the animal was relaxed and anesthetized. A tracheotomy was done, the right external jugular vein cannulated for starch injection, and the left femoral artery was cannulated for the purpose of drawing samples of blood for gas analysis. At 3:13 p.m. with the dog breathing room air, his respirations were 14 to the minute and his arterial blood was normally oxygenated, the percentage saturation being 92.8. One hour and forty-seven minutes later, after the dog had received intravenously $14.5 \mathrm{cc}$. of 1:4 starch suspension, his breathing had accelerated to 89 to the minute, he was cyanotic, and his arterial blood was $\mathbf{7 7 . 5}$ per cent saturated. The dog was then permitted to breathe 90 per cent oxygen. This resulted in a disappearance of the cyanosis. The arterial blood was no longer unsaturated but showed a percentage saturation of 96.8. In spite of this fact, his respirations had accelerated to 99 to the minute. On discontinuing the oxygen supply and allowing the dog to breathe room air once more, cyanosis became intense, the percentage saturation of arterial blood falling to 55.6, and the respirations growing extremely rapid and shallow-194 to the minute.

We believe that this experiment indicates that anoxemia is not primarily responsible for the occurrence of the rapid and shallow breathing of starch embolism. For here the rate continued at 99 to the minute without anoxemia though, to be sure, the further acceleration to 194 was undoubtedly the result of oxygen want. 
In another experiment this same point was brought out by a reduction in rate from 74 to 47 , upon breathing 90 per cent oxygenthe rate before embolism having been 18 . This reduction was associated with disappearence of anoxemia, but it is apparent that the primary cause of tachypnea which produced a rate of 47 still operated.

More convincing evidence of the fact that tachypnea following starch embolism occurs independently of anoxemia was furnished by an experiment in which a dog inhaled 83 per cent $\mathrm{O}_{2}$ and maintained completely saturated arterial blood throughout. In spite of this, the rate of his respirations rose from 14 to 50 after $9.5 \mathrm{cc}$. of 1:20 starch suspension had been injected intravenously.

These observations are consistent with the findings of Dunn, who observed in goats rapid breathing without anoxemia.

The cause of anoxemia following obstruction to the pulmonary circulation is fully discussed in Paper II of this series (16). It may be momentarily dismissed here since it has been shown that the rapid breathing in which we are primarily interested may occur independently of anoxemia. It remains, therefore, to inquire into the cause of tachypnea. In the introduction we have already considered the probable relation of rapid and shallow breathing to the reflex innervation of the lungs. As long ago as 1812 Legallois (17) observed that section of the vagus nerves produced slowing and deepening of the respiration. Hering and Breuer (5) as well as Head (7) showed that the reflex mechanism, which goes by their names, depends for its existence upon the function of the vagi. Gad (14) was the first to demonstrate that by freezing the vagus nerves their functional activity could be temporarily interrupted, subsequently to be restored by thawing. This method of physiological vagotomy has the twofold advantage over actual section of the nerves in that it eliminates complicating currents of injury induced at the cut ends of the nerves which, of themselves, alter the type of breathing, and in that subsequent thawing permits restoration of normal conduction.

\section{Method of vagal freezing}

A convenient method for freezing the vagi is to place under the isolated intact nerves a silver-plated tube $2 \mathrm{~mm}$. in diameter, so bent as to allow the nerves to lie in two concave depressions, with the dog's trachea disposed between them 
(see fig. 1). The tissues, other than the vagi, are insulated from the tube by cotton wool. Through this tube cold brine is permitted to flow, the temperature of which can be controlled by the proper admixture of a warmer brine solution.

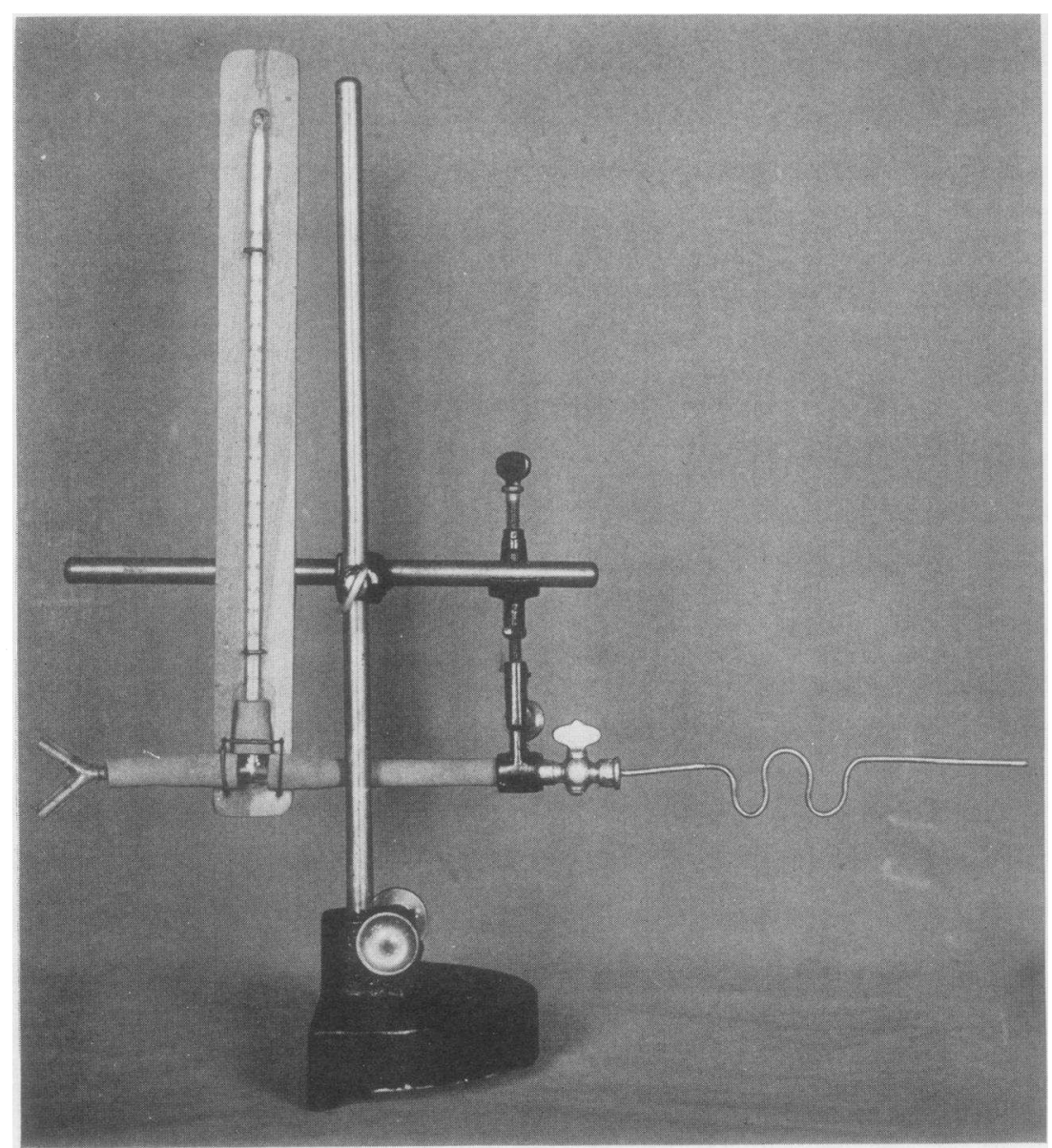

Fig. 1. Photograph of Bent Silver Plated Tube Through Which Cold Brine Flows-For the Purpose of Freezing the VAgus Nerves

The optimum temperature for freezing lies between $0^{\circ}$ and $-5^{\circ} \mathrm{C}$. At these temperatures subsequent thawing apparently restores the nerves to normal functional activity. 


\section{Effect of vagal freezing upon tachypnea following starch embolism}

Experiment 60. A dog anesthetized with Luminal Sodium was given $9.5 \mathrm{cc}$. of $1: 20$ starch suspension intravenously. His respiratory rate rose from 16 to 57 per minute. While breathing at this rate the isolated vagi were frozen by the method described, with the result that the rate of breathing immediately dropped to 20. The accompanying changes in tidal air were as follows: Before embolism 147 cc., after embolism 88 cc., after vagal freezing $170 \mathrm{cc}$.

The effect of this procedure is, therefore, to convert rapid, shallow breathing into slow, deep breathing, We might conclude from such an experiment that the physiological section of the nerves occasioned by freezing them blocked certain afferent peripheral impulses initiated by the presence of the starch emboli. We have, however, already cited evidence which casts doubt on the starch effect being primarily the result of afferent irritative impulses. It was shown that a certain mass of starch suspension had to be injected before tachypnea was precipitated. Unless we are dealing with a summation of inadequate stimuli this fact strongly suggests that the starch effect is a mechanical one, rather than irritative, resulting from obstruction to a certain portion of the pulmonary circulation -or, at least, from the anatomical changes secondary to such obstruction.

Effect of vagal freezing upon tachypnea due to central rather than peripheral stimuli. In order to find out whether the immediate subsidence of tachypnea brought about by vagal freezing after starch embolism necessarily indicated that the tachypnea had been due to afferent peripheral stimuli arising in the lung, a control experiment was planned in which rapid breathing was induced by central stimulation (anoxic anoxemia, inhalation of 10 per cent $\mathrm{CO}_{2}$ ). In this experiment there was no question of abnormal peripheral stimuli such as might result from starch embolism.

Experiment 63. A dog weighing $12.5 \mathrm{~kg}$. was given 1.9 gram Luminal Sodium by stomach tube. Two and one-quarter hours later when he was relaxed and anesthetized, a tracheotomy was performed and the left femoral artery was cannulated. The vagus nerves were exposed in the neck and placed on the freezing tube. The dog was then made to rebreathe a certain volume of air enclosed in a Benedict spirometer, equipped with inflow and outflow valves, the $\mathrm{CO}_{2}$ being continuously removed by passage of the expired air through soda lime. 
The result of this procedure was the gradual utilization of the oxygen in the spirometer until the animal developed oxygen want and consequent rapid breathing. At the height of rapid breathing, when the $\mathrm{O}_{2}$ concentration in the spirometer had fallen to 3.9 per cent, and the animal was deeply cyanosed, the vagi were frozen. This resulted in an immediate slowing and deepening of respirations. These facts were graphically recorded by the spirometer and are repro-

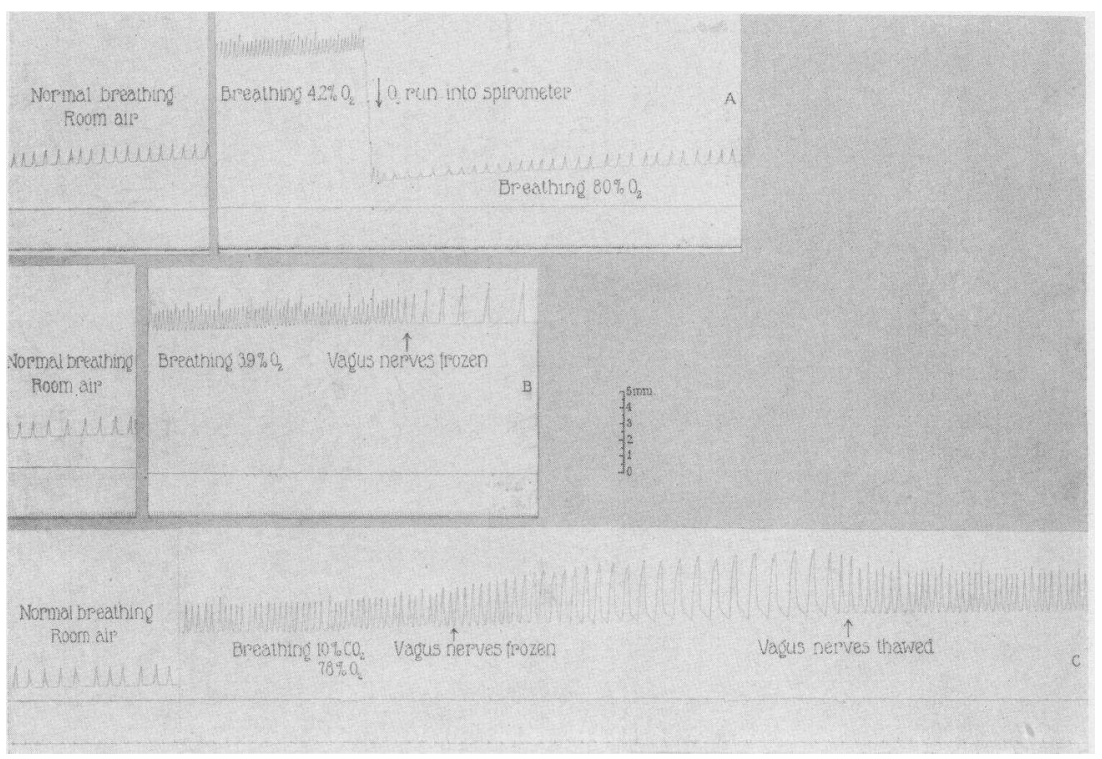

Fig. 2. The Effects on Respiration of a Low $\mathrm{O}_{2}$ Concentration, Vagal Freezing and High $\mathrm{CO}_{2}$ Concentration

Curve A shows the slowing effect on respiratory rate of adding 90 per cent $\mathrm{O}_{2}$ to the oxygen poor mixture in the spirometer. Time marker indicates 1 second intervals.

Curve B shows the slowing and deepening effect of vagal freezing on rapid respirations due to breathing an oxygen poor mixture. Time marker indicates 1 second intervals.

Curve $\mathrm{C}$ shows the slowing and deepening effect of vagal freezing on rapid breathing due to high $\mathrm{CO}_{2}$ concentration. Time marker indicates 5 second intervals. The factor for the spirometer is $4.82 \mathrm{~cm}$. excursion of the bell for 1 liter. The scale represents centimeters reduced proportionately to the tracing.

duced in figure 2, curve B. To show that the rapid respirations were due wholly to oxygen want in another such period of rebreathing when the $\mathrm{O}_{2}$ concentration of the spirometer had fallen to 4.2 per cent, 95 per cent oxygen was run into the spirometer with the result that rapid respirations immediately ceased. This is graphically shown in figure 2, curve A. 
This experiment, therefore, showed that rapid breathing due to oxygen want resulting from lowered alveolar oxygen tension can be at once stopped by freezing the vagus nerves. To find out whether vagal freezing checks the rapid breathing resulting from central stimuli other than anoxemia, the same dog was permitted to rebreathe a volume of 95 per cent oxygen enclosed in the Benedict spirometer from which the soda lime had been removed. The result was a gradual accumulation of $\mathrm{CO}_{2}$ without the development of $\mathrm{O}_{2}$ want because of the high $\mathrm{O}_{2}$ concentration. When the $\mathrm{CO}_{2}$ concentration had reached 10 per cent and the dog's breathing was rapid, the vagi were frozen and there resulted slow, deep respirations. The graphic spirometric tracing is reproduced in figure 2, curve $\mathrm{C}$.

This is in accord with the findings of Scott (10), who showed that the response to high $\mathrm{CO}_{2}$ inhalation after vagotomy was characterized by increase in depth rather than accelerated rate.

We believe that this experiment shows that since vagotomy slows the tachypnea of central origin, such slowing does not necessarily imply the blocking of afferent irritative peripheral impulses. And the slowing produced by vagal freezing in starch tachypnea cannot, therefore, be used as evidence for the existence of such impulses.

\section{PATHOLOGY OF STARCH EMBOLISM}

At this point a description of the pathological process produced in the lungs by starch embolism will be of advantage. It should be said that the potato starch granules are of variable shape and size, being, roughly circular to oval, and in diameter from 20 to 40 micra. In a starch suspension some granules were seen with a diameter as small as $\mathbf{5}$ micra and others as large as $\mathbf{6 0}$ micra. The diameter is such as to permit their entrance into terminal arterioles and capillaries, but the granules are apparently too large to pass beyond pulmonary capillaries. Starch cells have not been found on histological examination of organs other than the lungs. But in the lungs their distribution is widely disseminated. In some specimens they are frequently seen in almost every low power microscopic field, often completely oblitering the lumen of a capillary. A detailed description of the gross and microscopic pathology of the embolized lungs follows. 
Pathology of starch lungs. Postmortem examination was performed on 15 dogs which had received starch. In some instances the animals were killed at the conclusion of the experiment by injecting 10 to $20 \mathrm{cc}$. of a saturated solution of magnesium sulphate ${ }^{1}$ intravenously; in other cases they died spontaneously. Autopsy was performed immediately after death, the trachea being clamped before the chest was opened. The clamp was later removed and the collapse of the lungs noted.

Normal controls. Two normal dogs were sacrificed to serve as controls. These were anesthetized and fastened to the table for 3 hours, in a way comparable to the experimental animals. One of these died following decerebration, and the other was killed with magnesium sulphate intravenously.

The lung-heart ratio in the 2 normal controls was 1.42 and 1.10 respectively, the mean being 1.26. The pleural cavities contained no free fluid. The lungs were pale pink and collapsed completely on removing the tracheal clamp, except in small areas in the cephalic and ventral lobes. ${ }^{2}$ Only a slight degree of hypostasis occurred in the posterior of the caudal lobes of these animals. The right heart seemed moderately dilated.

\section{Gross pathology}

For convenience of description the material may be divided into two groups according to whether the animals died, or were killed, within 2 hours after the primary starch injection, or longer, $2 \frac{1}{2}$ to $4 \frac{1}{2}$ hours. Eight animals are included in the former, and 6 in the latter group.

Thorax and lungs. In the first group, i.e., in those dogs in which death occurred within 2 hours after the first starch injection, the lungs appeared normal except for more extensive hypostasis in the dependent parts. There was no marked congestion and no gross edema. The heart-lung ratio in 2 cases was 1.44 and 1.45 , respectively, which is within the normal limit. No free fluid was present in the pleural cavities.

In the second group of 6 animals, in which death occurred from $2 \frac{1}{2}$ to $4 \frac{1}{2}$ hours after the first starch injection, pleural fluid was present in excess in only 1 (25 cc.), but hypostasis was more extensive than in the first group in all. In $1 \mathrm{dog}$ hypostasis was so extensive as to involve the whole of both caudal lobes and the dependent (dorsal) parts of the other lobes. In all the animals of this group the

${ }^{1}$ For this method of killing dogs we are indebted to Colonel E. B. Vedder of the United States Medical Corps, Medical Research Division, Chemical Warfare Service. The method has the advantage of bringing about almost instantaneous death from respiratory failure and cardiac stand-still, without resulting structural changes in the lung attendant upon most other methods of killing animals.

${ }^{2}$ For convenience Theobald Smith's (18) classification of the lobes of the lungs is employed. On either side there is a cephalic ventral and caudal lobe, while on the right side there is, besides, a medial lobe. 
lungs collapsed on removing the tracheal clamp, but not to the same degree as in the normal dogs. There was, however, no generalized emphysema. Petechial hemorrhages occurred on the pleural and on the cut surfaces of the lungs in 4 instances. The hemorrhagic areas were bright red and measured approximately 3 to $4 \mathrm{~mm}$. in diameter. Edema was very marked in the lungs of 2 dogs, frothy serous fluid exuding in large quantity through the trachea when the lungs were inverted, and the cut surfaces appearing quite wet. The lung-heart ratio in these 2 was 4.63 and 3.85, respectively, well over the normal figure, and in 1 other it was 1.66.

Other organs. The right heart usually appeared dilated and tense. The spleen, liver and kidneys showed no lesions which could be attributed to starch injection.

Antemortem injection of India ink. In 1 case $25 \mathrm{cc}$. of Higgin's waterproof India ink, previously dialyzed in a parchment sac against Ringer's solution (Krogh (19)), was run into the jugular vein and the animal killed 5 minutes later by the intravenous injection of magnesium sulphate solution. Examination of these lungs after removal showed that the hypostatic areas in the lower lobe were red and had not been permeated by India ink. The remainder of the surface of the lungs was stippled with small black spots, a picture very different from that seen in a normal animal similarly injected with India ink. In a normal dog the surface of the lungs presented a diffuse black discoloration except along the edges where there was no India ink to be seen.

Postmortem injection of barium sulphate gelatin. The pulmonary arteries of 2 normal dogs and of 2 "starch" animals were injected postmortem by the method of Gross (20) with barium sulphate gelatin under 40 to $60 \mathrm{~mm}$. $\mathrm{Hg}$ pressure. The solution used, however, was less viscid than Gross's, having as its base 6 per cent gelatin, which is approximately isoviscid with blood. After fixation in 10 per cent formalin, stereoscopic $x$-ray photographs were made. The lungs were then cleared by the Spalteholtz (21) method.

Examination of steroscopic $x$-rays of the injected lungs of the normal dogs shows that the main arteries gradually diminish in calibre as they approach the periphery, and that they give off numerous small branches which similarly diminish in size to end in the fine arterioles at the surface. The structure may be compared to the branching of a spruce tree (see fig. 3). In the x-ray pictures of the starch lungs careful examination shows that the shadow cast by the fine threadlike terminal vessels is absent. This is demonstrated more clearly by inspection of the surface of the cleared specimens with a lens (see figs. 4 and 5). There is also a noticeable difference in color between the cleared normal and starch specimens. The starch lungs are much darker than the normals, due to retained blood which has not been completely washed out by the preliminary saline irrigation. 


\section{Microscopic pathology}

Lungs. (See fig. 6.) Histological examination was made in 13 cases. After the lungs had collapsed sections from several lobes were fixed in Zenker's fluid with 5 per cent acetic acid. Eosin and methylene blue staining was used on

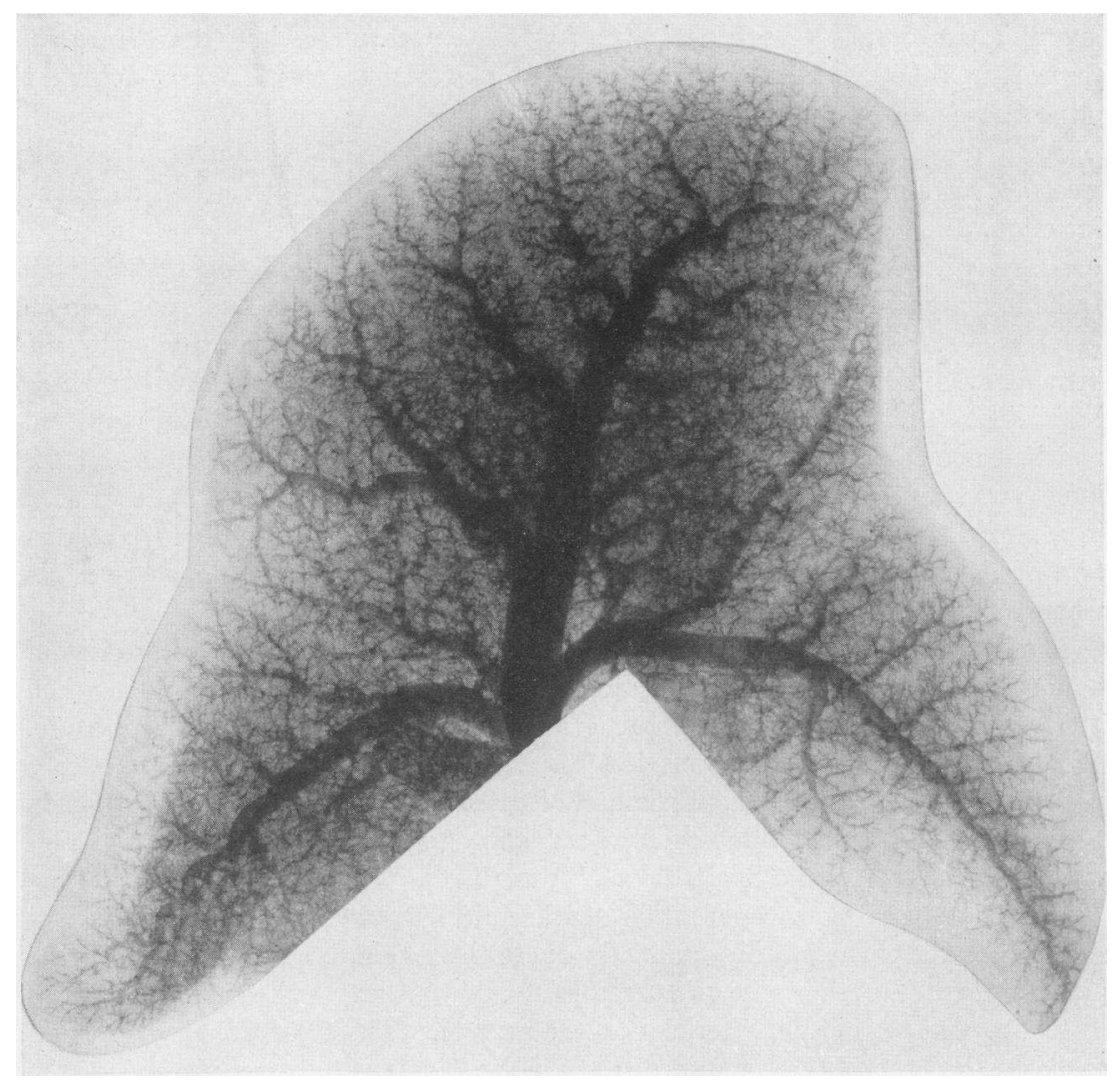

Fig. 3. Dog 6. Starch Injection. X-ray Photograph of Cephalic, Ventral and Medial Lobes of Right Lung after InjecTION With Barium Sulphate Gelatins

Note the type of branching of the pulmonary artery in the dog's lung

paraffin embedded sections. In some instances frozen sections were stained with Gram's iodine.

The starch granules were seen in the arterioles and capillaries scattered throughout all lobes, the majority appearing to be in arterioles. Those in the capillaries 


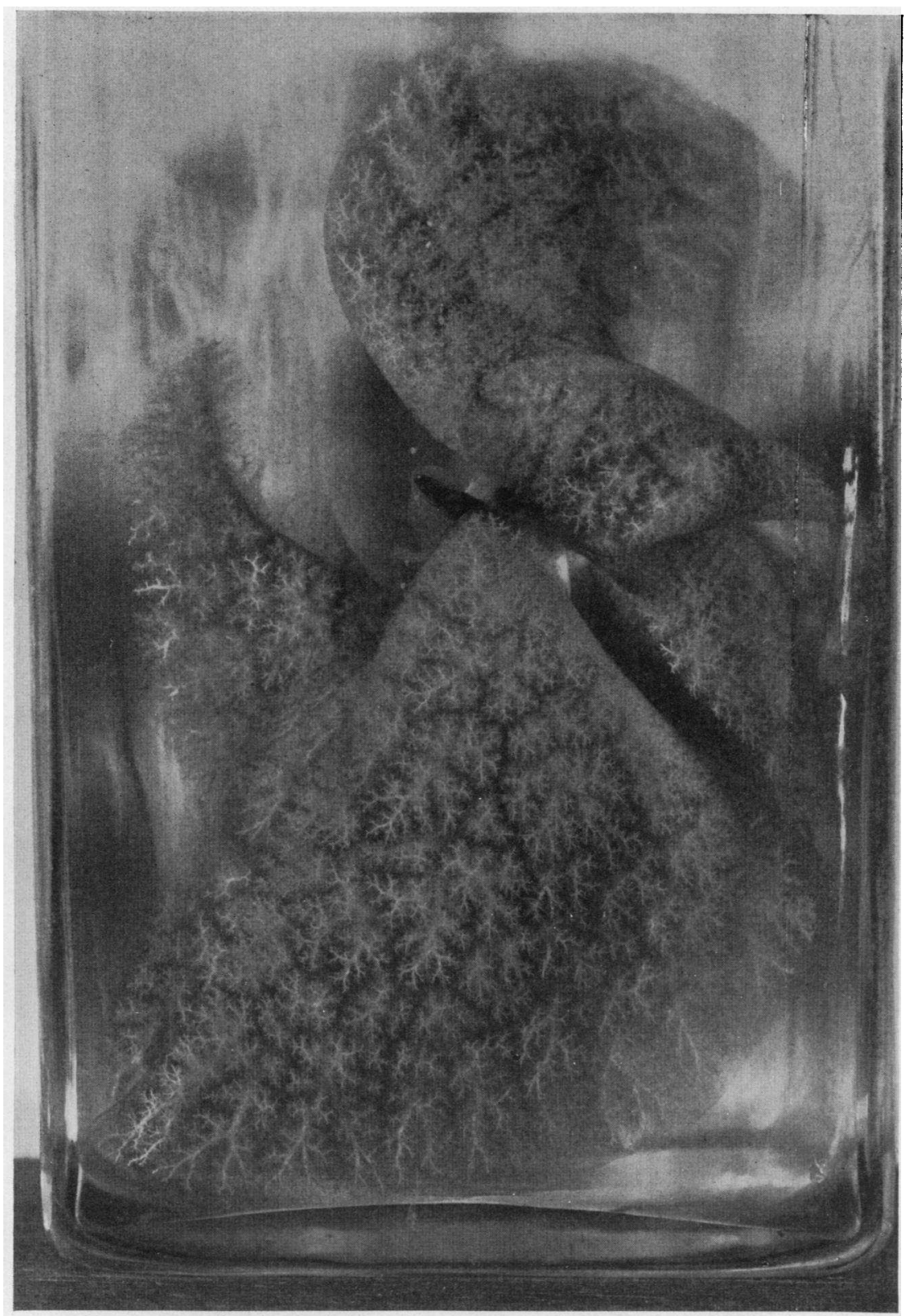

Fig. 4. Dog C. 1. Normal Control. Natural Size Photograph of Surface of InJected aNd Cleared Right Lung

Note the fine pheripheral vessels. The animal was bled to death and the right pulmonary artery irrigated with saline at 30 to $40 \mathrm{~mm}$. $\mathrm{Hg}$ pressure until the return venous flow was colorless. It was then injected with hot 6 per cent barium suphate gelatine at 50 to $60 \mathrm{~mm}$. $\mathrm{Hg}$ pressure and fixed in formalin, dehydrated and cleared in oil of wintergreen. 


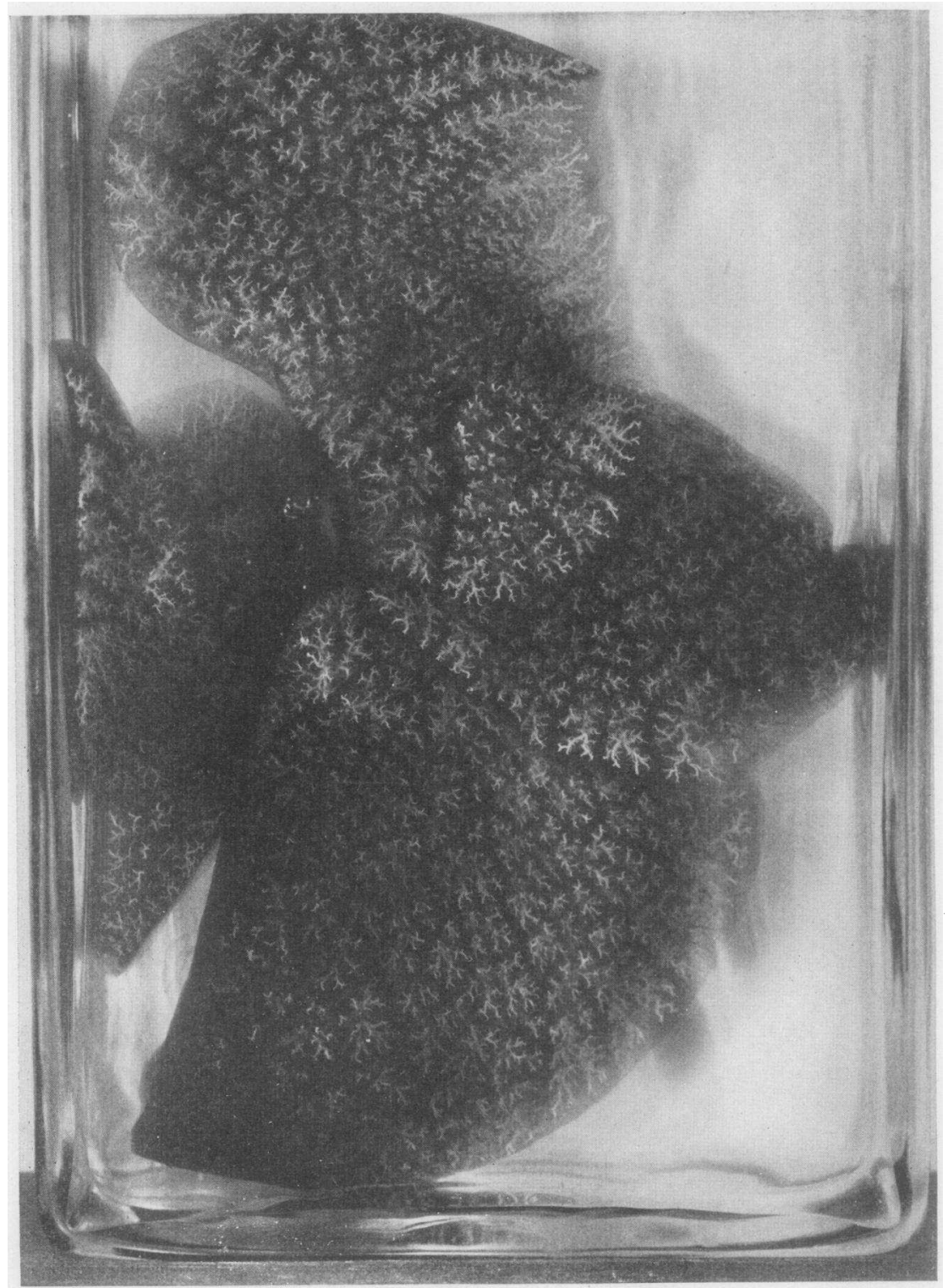

Fig. 5. Dog 16. Natural Size Photograph of "Starch" Lung Note the absence of the finer arteriole twigs-and the dark color due to retained blood. 


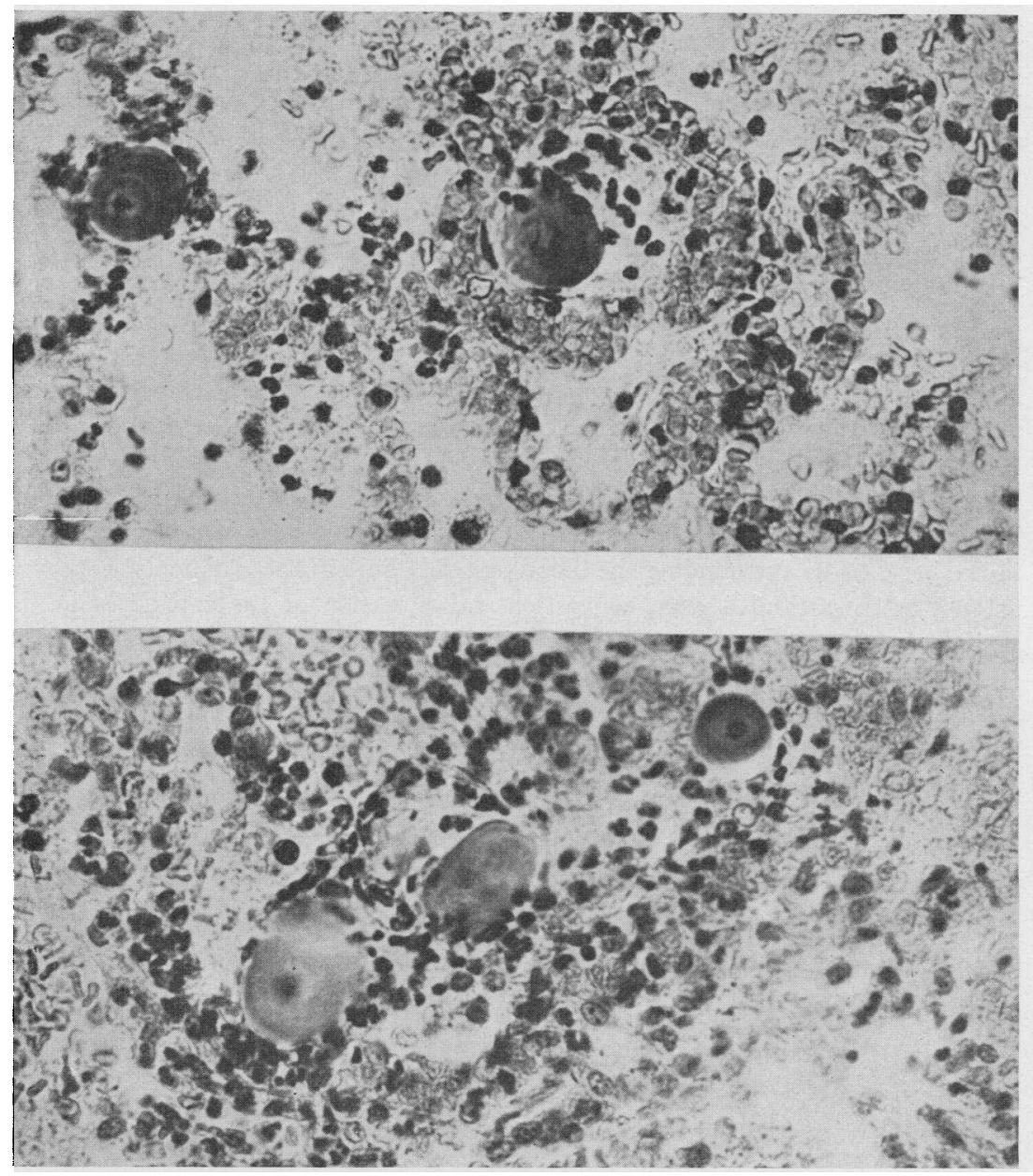

Fig. 6. Dog 21. "Starch" Lung. Microphotograph of Right Ventral LOBE. $\times 430$

Grossly the lung showed petechial hemorrhages and edema.

A. Note the two starch granules with surrounding leucocytic thrombi. The great local dilatation of the capillaries is also evident.

B. The later stage of the above. Note the extravasation of red blood cells into the alveolar lumina which also contain a serous fluid and some leucocytes. 
caused definite dilatation of the walls and bulging into the alveolar lumina. The number of granules varied greatly in different specimens, sometimes occurring in every low power field, sometimes not so frequently. Frequently small leucocytic thrombi could be seen about the granules. An interesting finding was the irregular narrowing of the lumina of the bronchioles, due to local thickening of the musculature. This was likewise observed by Dunn who believed it represented muscular spasm. The significance of these contractions is doubtful, since they were found also in the lungs of the normal dogs.

In the 7 dogs in which death occurred within 2 hours after the first starch injection the characteristic findings were those just described. Besides these, in 4 instances areas of congestion and partial atelectasis were seen about the starch emboli. In these congested areas capillaries were distended and the alveolar walls thickened. Interstitial edema occurred in 2 of these 4 dogs and in 1 other of this group.

On the other hand, in each of the 6 cases in which death occurred $2 \frac{1}{2}$ to $4 \frac{1}{2}$ hours after the first starch injection, interstitial edema was present, especially in the loose tissue surrounding the blood vessels. In 4 of these animals there was, as well as interstitial edema, congestion and dilatation of the capillaries in the region of the starch emboli with extravasation of fluid and red blood cells into the alveolar spaces. The walls thus thickened encroached on the alveolar lumina. Emphysema did not occur except in small areas near the surface.

The above description does not include sections of the hypostatic areas which showed hemorrhagic extravasation into the alveolar spaces.

\section{Blood pressure following starch embolism}

From the obstruction to the pulmonary circulation observed in these pathological specimens it seemed at first probable that starch embolism might lead to profound changes in systemic and pulmonary blood pressures and that the rapid breathing following starch injection might be related to such changes. Dunn (13), however, had shown that no rise in right ventricular pressure occurred in goats after starch embolism, and that there was no conspicuous change in venous or arterial blood pressures. Since these findings are quite consistent with the work of previous investigators, Lichtheim (22), Welch (23), Underhill (24), we have not at this time deemed it necessary to inquire into changes in the pressure in the pulmonary circulation for an explanation of tachypnea. Measurement of the pressure in the pulmonary circulation usually requires operative procedures which may in themselves occasion changes in respiratory rates. Haggart and Walker (25) have recently shown that until from 52 to 66 per cent of the pulmonary 
circulation is cut off by clamping the pulmonary artery there is no significant variation in the general circulatory condition of the animals (cats). At this point a minute increase in arterial obstruction leads to circulatory collapse with dilatation of the heart and fall in pulmonary and arterial pressure.

In 2 dogs receiving intravenous starch injection we observed only a very slight lowering of systemic blood pressure after the onset of tachypnea. In 1 of these animals raising the arterial blood pressure by intravenous injection of adrenalin was without effect on tachypnea, showing that this condition is certainly not related to a shock-like fall in systemic blood pressure. Figure 7 presents the blood pressure and

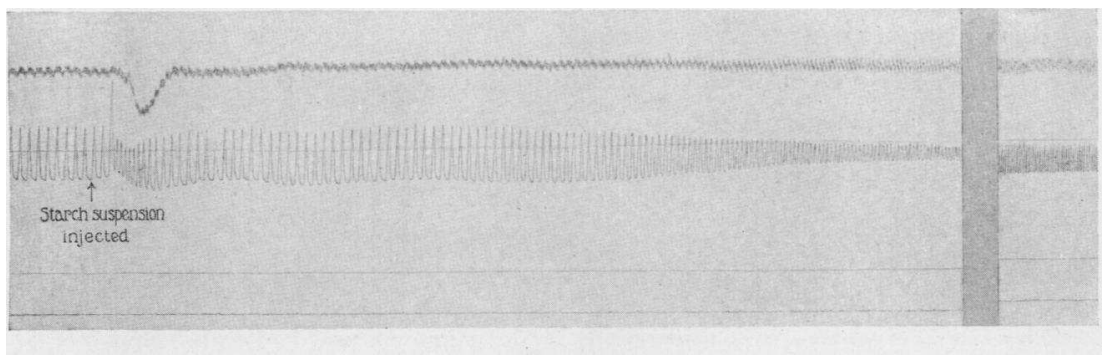

Fig. 7. Blood Pressure and Pneumographic Tracing before and after Injection of 5 cc. 1:4 Starch Suspension.

The mean arterial pressure remains practically unchanged. The increase in pulse pressure, decrease in diastolic pressure and marked acceleration of respiratory rate are shown. Time marker indicates 1 second intervals.

pneumographic tracing of one of these experiments. After the injection of 5 cc. 1:4 starch suspension there is an immediate drop in systemic pressure which quickly resumes the normal level, to be followed (with onset of tachypnea) by slight lowering of diastolic and increase in pulse pressure, the mean arterial pressure remaining practically unchanged.

\section{Reduction of lung volume following starch embolism}

The general picture of congestion suggested a probable change in the elasticity of the lung, such as shows itself in clinical disease by a reduction in vital capacity. Since a measurement of vital capacity 
requires active coöperation on the part of the subject, it is hardly possible in experimental animals. We were, however, able to measure the volume of air in the lungs at the end of expiration, or the so-called functional residual air (3). This, we know, in man, forms a constant fraction of the total lung volume and varies with it as it does with the vital capacity. In 3 successive lung volume determinations in a normal dog the extreme variations were from 0.55 to 0.52 liter, indicating that the method is reliable when used on animals. A marked reduction of lung volume was observed in a dog which had received an intravenous injection of 9 cc. 1:4 starch suspension. Before injection, when the respiratory rate was 30 , the lung volume was 0.52 liter. After starch injection the rate doubled and the lung volume decreased to 0.36 liter, a drop of 30 per cent. One may conclude from this that the hypostasis, edema and swelling of capillaries which has led to atelectasis thereby results in a diminution in air content of the lungs. The probable relation of this to rapid and shallow breathing will be discussed.

\section{DISCUSSION}

The experiments presented in this paper, we believe, bring out certain facts concerning the causes of rapid and shallow breathing. It has been shown that following the production of multiple emboli of the pulmonary arterioles and capillaries, rapid and shallow breathing ensues. This may be aggravated by anoxemia but does not depend for its existence upon the occurrence of anoxemia. It was thought at the outset that the change in respiratory rate and depth was probably the result of irritative stimuli in the lungs occasioned by the presence of starch granules, and that the effect of vagal freezing which promptly slowed and deepened respiration was to block these afferent stimuli. Two facts which we have observed make us question this interpretation. First, the onset of tachypnea did not occur until a certain volume of starch suspension had been injected, at which time there was gradual acceleration up to a maximum rate. This suggested that the response was related to the mechanical obstruction of the pulmonary circulation, or to the secondary anatomical changes dependent thereon, and that it was not of an irritative reflex nature which might be expected to operate immediately and proportionately to the 
dosage. The second fact which occasioned doubt as to whether the tachypnea of starch embolism were induced by afferent irritative stimuli was this: Other types of tachypnea dependent upon what are probably central stimuli such as anoxic anoxemia and high carbon dioxide concentrations and not dependent upon the presence of foreign bodies in the lungs, are similarly stopped by vagal freezing. This, we believe, suggests that an animal whose vagus nerves have been cut or frozen is unable normally to accelerate his respirations, and that he responds chiefly to the fundamental rhythm of the respiratory center which can no longer be notified of changes in the degree of distention and collapse of the lungs, since the Hering-Breuer reflex has been intercepted by vagotomy. We have been unable to convince ourselves that the contractions of bronchial musculature which Dunn (13) believed to be of importance are the essential lesions responsible for tachypnea since similar contractions were observed in postmortem examination of the lungs of control dogs.

The whole pathological picture in the lungs of these animals is one of vascular congestion and interstitial edema-with localized areas of atelectasis. These changes are accompanied by diminution in lung volume and are, we believe, analogous to those seen in disease in human beings in which pulmonary congestion results in loss of elasticity of lung tissue (Lungenstarre) associated with a reduction of the vital capacity.

The structural changes resulting in reduced lung volume because of diminished pulmonary elasticity result in mechanical limitation of the depth of the individual breath. Thus we see that those conditions in which reduction of lung volume occurs, such as acute and chronic passive congestion of the lungs, lobar pneumonia, pulmonary fibrosis, are the very ones in which the respirations are liable to be shallow and rapid: Shallow because of mechanical limitation to distension and collapse; and rapid, we believe, because the normal selfregulating mechanism of Hering and Breuer by which each respiratory phase is terminated and the reverse phase liberated, is sped up by the mechanical limitation of each phase. A clearer description of this process is at present hardly possible since we are ignorant of the exact nature of the stimulus to which the Hering-Breuer reflex responds. That some such such sequence of events can actually occur may be 
very simply shown by compressing an anesthetized dog's thorax with the hands or by wrapping an ordinary blood pressure cuff about the thorax and inflating the cuff. Under these conditions the greater the compression, the shallower the breathing, and the shallower the more rapid. This effect is instantaneous and, therefore, almost certainly not the result of chemical changes in the blood or respiratory center. This we conceive to be the mechanism of rapid and shallow breathing as it occurs in multiple experimental embolism of the pulmonary arterioles and capillaries. The condition may be aggravated by anoxemia, but, on the other hand, it may arise independently of anoxemia.

The fact that freezing the vagus nerves will convert such rapid and shallow breathing into slow, deep breathing can be explained on the basis of interference with the Hering-Breuer reflex, with the result that the respiratory center is no longer apprised of the postural state of the lungs. Breathing takes on the fundamental rhythm of the center which tends to be characteristically slow and deep, without the moderating influence of the vagi, and which can, under these conditions, overcome the lung's resistance to distension. It must, of course, be remembered that central stimuli due to the hydrogen ion concentration of the blood and the metabolic needs of the organism will, in part, determine the respiratory rate when depth is limited from whatever cause, no mechanical reflex explanation being sufficient.

It is not improbable that the explanation of the cause of rapid and shallow breathing suggested here obtains likewise in such clinical conditions as acute and chronic passive congestion of the lungs, lobar pneumonia, miliary tuberculosis, pulmonary fibrosis-conditions in which structural changes in the parenchyma lead to loss of elasticity and thus reduction in lung volume, with shallow (and therefore rapid) respirations. To establish this clinical analogy more securely it will be necessary to study the effects of similar experimental structural changes localized in one or more lobes. Such work is in progress, as well as an investigation of the effects of prolonged rapid and shallow breathing with particular reference to the question of fatigue of the respiratory center. 
1. Multiple emboli of the pulmonary arterioles and capillaries experimentally produced in dogs by the intravenous injection of suspensions of potato starch result in rapid and shallow breathing.

2. Such rapid and shallow breathing may be associated with anoxemia of the arterial blood.

3. It does, however, not depend upon anoxemia because rapid and shallow breathing persists after anoxemia has been relieved; and because it occurs even when anoxemia has been prevented by previous oxygen inhalation.

4. The cause of rapid and shallow breathing following embolism of the pulmonary arterioles and capillaries is therefore not anoxemia.

5. Freezing the vagus nerves converts the rapid and shallow breathing of starch embolism into slow, deep breathing.

6. This slow, deep breathing does not alleviate the condition of anoxemia which indicates that anoxemia is not caused by rapid and shallow breathing. The cause of anoxemia following obstruction to the pulmonary circulation is discussed in Paper II of this series.

7. Freezing the vagus nerves of a dog breathing rapidly from oxygen want, due to inhalation of a gas mixture with a low partial pressure of oxygen, similarly results in slow, deep breathing.

8. The same effect is produced by freezing the vagi of a dog with tachypnea caused by breathing a gas mixture with a high partial pressure of $\mathrm{CO}_{2}$.

9. This slowing effect produced by vagal freezing does therefore not necessarily represent the result of blocking afferent irritative peripheral impulses, since in these two instances (7 and 8) the stimulus to rapid breathing was central and chemical.

10. It is believed that a dog with vagi frozen is unable to accelerate his respiratory rate.

11. Evidence against the starch effect being of an irritative nature is furnished by the fact that a certain critical dose of starch suspension must be injected before the characteristic response of tachypnea occurs.

12. The gross and microscopic pathology of "starch" lungs is characterized by evidences of congestion, edema, and atelectasis with multiple emboli occurring in the arterioles and capillaries. 
13. These changes are not associated with a fall in systemic blood pressure.

14. They are associated with a reduction in lung volume (functional residual air) which is believed to be accompanied by a decreased elasticity of the pulmonary parenchyma.

15. Such a decrease in elasticity (Lungenstarre) results in shallow tidal air.

16. Breathing which is shallow becomes rapid through the mechanism of the Hering-Breuer reflex which depends for its existence upon intact vagus nerves.

17. This has been shown by compressing the thorax of an anesthetized dog under which circumstances the greater the pressure the shallower the breathing and the shallower the more rapid.

18. An analogy has been suggested between the cause of tachypnea following multiple embolism of pulmonary arterioles and capillaries and the rapid breathing seen in such clinical conditions as acute and chronic congestion of the lungs, lobar pneumonia, miliary tuberculosis, pulmonary fibrosis.

\section{BIBLIOGRAPHY}

1. Haldane, J. S., Meakins, J., and Priestly, J. G. Jour. Physiol., 1919, lii, 433.

2. Meakins, J. Arch Int. Med., 1920, xxv, 1.

3. Binger, C. A. L., and Brow, G. R. Jour. Exper. Med., 1924, xxxix, 677.

4. Hastings, A. B., Neill, J. M., Morgan, H. J., and Binger, C. A. L. Proc. Soc. Exper. Biol. and Med., 1923, xxi, 66; Jour. Clin. Invest., 1924, i, 25.

5. Hering, E., and Breuer, J. Sitzber. Wien. Akad., 1868, lvii and lviii.

6. Lumsden, T. Jour. Physiol., 1923, lvii, 153 and 354; lviii, 81 and 111.

7. Head, H. Jour. Physiol., 1889, x, 279.

8. Porter, W. H., and Newburgh, L. H. Amer. Jour. Physiol., 1916, xlii, 175; 1917, xliii, 455.

9. Sũner Pi, A. Jour. de Physiol. et de Path. Gen., 1919-1920, xviii, 702.

10. Scott, F. H. Jour. Physiol., 1908, xxxvii, 301.

11. Sũner Pi, A., and Bellido, J. M. Jour. de Physiol. et de Path. Gen., 1921, xix, 214.

12. Haldane, J. S. Respiration, New Haven, 1922, 56-57.

13. Dunn, J. S. Quart. Jour. Med., 1920, xiii, 129.

14. Gad, J. Arch. f. Physiol., 1880, 1.

15. Guttmann, P. Arch. f. Physiol., 1875, 502. 
16. Binger, C. A. L., Brow, G. R., and Branch, Arnold. Jour. Clin. Invest., 1924, i, 155.

17. Legallois, C. J. J. Experiences sur la principe de la vie, Paris, 1812.

18. Smith, T. Jour. Med. Res., 1913, n.s., xxiv, 291.

19. Krogh, A. A. Anatomy and Physiology of the Capillaries, New Haven, 1922, 39.

20. Gross, L. Jour. Med. Res., 1917, xxxi, 333. The Blood Supply of the Heart, New York, 1921, 4-10.

21. Spalteholz, W. Verhandl. d. anat. Gesellsch., Wurzburg, 1907, 21 Vers.

22. Lichtheim, L. Die Störungen des Lungenkreislaufes und ihr Einfluss auf den Blutdruck, Inaug. Dissert., Berlin, 1876.

23. Welch, W. H. Virchow's Arch. f. path. Anat., 1878, lxxii, 375.

24. Underhill, S. W. F. Brit. Med. Jour., 1921, ii, 779.

25. Haggart, G. E., and Walker, A. M. Arch. Surg., 1923, vi, 674. 